\title{
Mediators and Moderators of Parental Involvement on Substance Use: A National Study of Adolescents
}

\author{
Colleen C. Pilgrim, ${ }^{1,2}$ John E. Schulenberg, ${ }^{1}$ Patrick M. O'Malley, ${ }^{1}$ \\ Jerald G. Bachman, ${ }^{1}$ and Lloyd D. Johnston ${ }^{1}$
}

Published online: 30 March 2006

\begin{abstract}
Current social developmental theories of drug use often incorporate mediation processes, but it is generally unknown whether these mediation processes generalize across ethnicity and gender. In the present study, we developed a mediation model of substance use based on current theory and research and then tested the extent to which the model was moderated by gender and ethnicity (African American, European American, and Hispanic American), separately for 8th and 10th graders. The respondents were adolescents from the 1994, 1995, and 1996 cohorts of the Monitoring the Future (MTF) project, which conducts yearly inschool surveys with nationally representative samples. Multi-group, structural equation modeling (SEM) results indicated much similarity across gender and ethnicity for school success and time spent with friends as partial mediators of risk taking and parental involvement on drug use (controlling for parental education). However, there were some differences in the magnitude of indirect effects of parental involvement and risk taking on substance use for 8th-grade African American girls. Discussion focuses on the potential success of prevention efforts across different ethnicities and gender that target parent-child relationship improvement and risk taking, and considers possible culture- and gender-specific issues.
\end{abstract}

KEY WORDS: substance use; adolescents; ethnicity; parental involvement.

\section{INTRODUCTION}

A better understanding of the social developmental processes of adolescent substance use among different ethnic groups will help prevention efforts targeted for the increasingly multi-ethnic population in the United States. Although some studies have examined substance use across ethnicity, few studies have attempted to examine mediation models of substance use that are consistent with current social developmental theories. Many studies provide descriptive reports of ethnic differences in substance use rates, but even if there are ethnic differences in the rates of substance use, this does not imply that the processes leading to adolescent substance use are dif-

\footnotetext{
${ }^{1}$ Institute for Social Research, University of Michigan, Ann Arbor, Michigan; e-mail: cpilgrim@schoolcraft.edu.

${ }^{2}$ Correspondence should be directed to Colleen C. Pilgrim, Survey Research Center, Institute for Social Research, University of Michigan, Ann Arbor, Michigan 48106-1248; e-mail: cpilgrim@schoolcraft.edu.
}

ferent across ethnic groups (Rowe et al., 1994). And even those studies that examine ethnic difference by comparing direct effects across groups still cannot fully consider whether mediation models are similar across ethnicity. The present study addresses this issue by examining the extent to which mediational models of parental involvement effects on substance use are moderated by gender and ethnicity.

\section{Mediation Theories of Substance Use}

Theories with a mediation focus often assert that inept parenting or poor family relations lead to socially unskilled adolescents or adolescents without ties to conventional society, who are consequently more likely to do poorly in school and thus be accepted into a deviant peer group in which substance use occurs (Hawkins \& Weis, 1985; Patterson et al., 1989; Thornberry, 1987). Many of these theories have their roots in "social control theory," which suggests 
that individuals refrain from committing acts of deviance because of social and cultural constraints on their behavior and thus weak attachment to parents leads to increased deviance (Hirschi, 1969). Current theories differ in aspects upon which they primarily focus, but an underlying premise is one in which the effects of family relationships on drug use are mediated by school and peer relations. Thus, the present study seeks to determine whether such mediation processes generalize across ethnicity and gender.

The desire to engage in sensation-seeking activities has frequently been shown to be a strong predictor of adolescent substance use (Crawford et al., 2003; Zuckerman, 1994). Thus, the propensity to engage in risk-taking behaviors is viewed as one of the many risk factors for adolescent problem behavior, and the desire for risk taking is positively correlated with substance use (Hawkins et al., 1992). A newer direction has been to understand the dynamics and linkages between these risk and protective factors, including both indirect and direct effects (Jessor, 1998; Schulenberg et al., 2001). So in the current study, we also examined whether risk taking was mediated by school and peer factors and to what extent the findings generalized across gender and ethnicity.

\section{Gender}

Because gender roles affect a child's psychological development, potential gender interactions should be considered in social developmental theories of substance use. Also, even though a given risk factor may be related to substance use for both genders, it is important to understand whether there are any differences in the magnitude of such effects for female and male adolescents. For example, while researchers have found that conventional bonds (including high parental involvement and monitoring) are associated with lower levels of substance use during adolescence (Erickson et al., 2000; Reifman et al., 2001), some researchers have reported differences in parental influence on substance use for girls and boys (Jacobson \& Crockett, 2000; Li et al., 2000).

\section{Ethnicity}

A more ecological framework can help us address whether theories about substance use, which have been based primarily on adolescents of European descent, apply to other ethnic groups.
Some risk and protective factors related to adolescent substance use may be pertinent only for certain ethnic groups, while others such as peer and family networks as well as school-related domains may be common across all ethnic groups (Strait, 1999). Primary socialization theory asserts that parents, school, and peer clusters are the critical socializing forces for adolescent drug use and delinquency in Western culture, and thus these are most likely important across all ethnic groups in the United States (Oetting \& Donnermeyer, 1998).

It may be, however, that differences in key values among ethnic groups within the United States foster differences among adolescents in their substance use. For example, the concepts of collectivism and individualism, which have been long studied in the cross-cultural field, have recently appeared in substance use literature (Morgan-Lopez et al., 2003). The emphasis in collectivist societies tends to be on sharing experiences and supporting and helping in-group members, such that the evaluation of one's actions is in terms of the consequences to the in-group (Pilgrim \& Rueda-Riedle, 2003). "Individualism," on the other hand, is related to the evaluation of one's actions in terms of consequences to the individual. It is possible that U.S. adolescents from ethnic groups that embrace a more collectivist value would be less likely to engage in health-compromising behaviors because such would be viewed as negative by others in the adolescents' collectivist community. Because models for prevention and treatment of substance use typically do not consider these and other important cultural variables, there has been a call for prevention scientists to develop more "culturally rich" models (Castro \& Hernandez, 2002).

\section{Direct Effect and Mediation Studies}

The majority of researchers examining ethnic differences in the processes of adolescent substance use have focused on the direct effects of various risk and protective factors that have previously been linked to substance use with European Americans, such as family, personality, school, and peer domains. Much of this research has documented more similarities than differences across ethnic groups (Avenevoli et al., 1999; Bray et al., 2001; Costa et al., 1999; Gottfredson \& Koper, 1997; Herman et al., 1997; Roski et al., 1997) but some do report differences (Griesler \& Kandel, 1998; Pilgrim et al., 1999; Vega et al., 1998). Overall, studies of direct effects suggest 
similarity across ethnicity in the developmental processes of substance use, but of course, this cannot be assumed only by an examination of direct relationships between predictors and substance use.

Fewer studies have used mediation studies to determine the generalizability of social developmental theories across ethnic groups. While some have found similarity across ethnicity in the mediation process of peers and schools (Brook et al., 1997; Flannery et al., 1996; Wang et al., 1995; Wills, 2004) others have found some ethnic group differences (Murguia et al., 1998; Swaim et al., 1998). The mixed results of these studies suggest the need for further examination of ethnicity and gender as critical moderators, especially within nationally representative samples.

\section{Current Study}

The first objective of the current study was to test the extent to which the effects of parental involvement and risk taking on adolescent drug use were mediated by school success and time spent out with friends. As shown in Fig. 1, our hypothesized model includes pathways from parental involvement to both school success and time spent with friends in order to test for indirect effects of parental involvement on drug use. Similarly, pathways from risk taking to school success and time spent with friends were included to test for indirect effects of risk taking on drug use. Pathways from parental involvement to drug use and risk taking to drug use were also included because of the possibility that these predictors have a direct impact on adolescent drug use or that other potential mediators were also operating. Alternative models were examined to determine whether our conceptual model provided the best fit for the data, and these analyses along with other preliminary analyses are discussed in the Results section. The hypothesized model was developed with a nationally representative sample of adolescents (from 1996), and then tested with a separate nationally representative sample (from 1994 and 1995, combined).

Our second objective was to examine the extent to which our hypothesized model replicates across gender and ethnicity (African American, Hispanic American, and European American adolescents) with 8th and 10th graders. Most past studies examining mediation processes across ethnicity have used small or non-representative samples, rais-

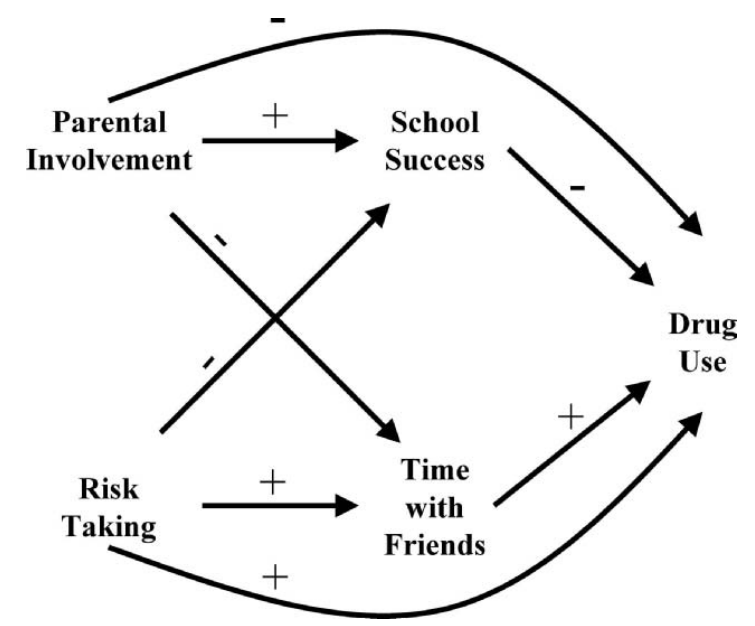

Fig. 1. Hypothesized model.

ing questions about generalizability. Thus, the current study adds to our scientific knowledge by examining the generalizability of mediation processes of substance use across ethnicity and gender with large, nationally representative samples of adolescents.

\section{METHOD}

\section{Participants and Procedures}

The current study used 8th- and 10th-grade data from the 1994, 1995, and 1996 cohorts of the Monitoring the Future (MTF) project conducted by the Institute for Social Research at the University of Michigan (Johnston et al., 2004). The MTF project has conducted yearly in-school surveys with nationally representative 12th-grade samples since 1975 and 8th- and 10th-grade samples since 1991.

Questionnaires were administered by trained University of Michigan interviewers during school hours each year in late winter or spring, usually in a regularly scheduled class period. Special procedures were used to ensure confidentiality; these procedures were explained carefully in the questionnaire instructions and reiterated by the interviewers. Individual participation rates for the 1994, 1995, and 1996 surveys ranged from 87 to $91 \%$ of the school population (with virtually all non-participation due to absence from school). ${ }^{3}$ Johnston et al. (2004) report that absentees have higher than average drug

\footnotetext{
${ }^{3}$ In terms of items used in the current study, item non-response rates ranged from $<1$ to $5 \%$ with the exception of the
} 
use levels. However, even among 12th graders, the absentees are a small proportion of the total (about $17 \%$ ), and reweighting to adjust for absenteeism made corrections that appeared to be of little or no substantive significance in estimated drug use levels. The smaller proportions of absentees at grades 8 and $10(9-13 \%)$ would suggest even less of an impact. Moreover, the covariances would be affected even less than the mean levels. We therefore opted not to reweight for absenteeism.

Two questionnaire forms were used each year, and each version was administered to a random half of the sample within each classroom. Because of item availability, only one form was used in these analyses, and thus the current study is based on half of the total sample. Because the study uses a three-stage random sampling procedure (Kish, 1965), weights were assigned to compensate for differential probabilities of selection at each stage. Additional study procedures are described in detail elsewhere (Bachman et al., 2001; Johnston et al., 2004).

\section{Measures}

The wording and response options for all items can be found in Table 1. Cronbach alphas reported below were computed from the 1996 sample $(N=$ $13,244)$ for 8 th and 10th graders.

\section{Drug Use}

Drug use was measured with three items that assessed the frequency of smoking cigarettes, drinking alcohol, and using marijuana in the last 30 days $(\text { Cronbach alpha }=.74)^{4}$.

sensation-seeking items; because these are at the end of the questionnaire, they have a larger non-response (approximately 23 and $12 \%, 8$ th and 10 th grades, respectively). To ensure that our sample was still representative, at least in terms of relationships among variables of interest, we compared the item covariance matrices (excepting the sensation-seeking items) for those students with the sensation-seeking items to those without; the covariances were virtually identical and no significant differences were found.

${ }^{4}$ The final model, with 30-day drug use as a latent construct comprised of cigarette, alcohol, and marijuana use, was compared with three separate models where drug use was a single indicator for each drug (i.e., cigarette use, alcohol use, or marijuana use). Findings from these single-indicator models were similar to those reported in this study for the latent three indicator construct.
Table 1. Latent Construct with Constituent Items and the Standardized Factor Loadings

\begin{tabular}{|c|c|c|}
\hline & \multicolumn{2}{|c|}{ Grade level } \\
\hline & 8 th & 10th \\
\hline \multicolumn{3}{|l|}{ Parental involvement ${ }^{a}$} \\
\hline \multicolumn{3}{|l|}{$\begin{array}{l}\text { How often do your parents (or step-parents or } \\
\text { guardians) do the following... }\end{array}$} \\
\hline $\begin{array}{l}\text { Check on whether you have done your } \\
\text { homework/Provide help with your } \\
\text { homework when it's needed. (items } \\
\text { combined) }\end{array}$ & .63 & .54 \\
\hline $\begin{array}{l}\text { Require you to do work or chores around the } \\
\text { house }\end{array}$ & .43 & .43 \\
\hline $\begin{array}{l}\text { Limit the amount of time you can spend } \\
\text { watching TV }\end{array}$ & .52 & .59 \\
\hline \multicolumn{3}{|l|}{ Risk taking $^{b}$} \\
\hline $\begin{array}{l}\text { I like to test myself every now and then by } \\
\text { doing something a little risky }\end{array}$ & .83 & .85 \\
\hline $\begin{array}{l}\text { I get a real kick out of doing things that are a } \\
\text { little dangerous }\end{array}$ & .75 & .77 \\
\hline \multicolumn{3}{|l|}{ School success } \\
\hline \multicolumn{3}{|l|}{$\begin{array}{l}\text { Now thinking back over the past year in } \\
\text { school, how often did you... }\end{array}$} \\
\hline Try to do your best work in school? ${ }^{c}$ & .56 & .61 \\
\hline $\begin{array}{l}\text { Fail to complete or turn in your } \\
\text { assignments? }^{c}(\mathrm{rev})\end{array}$ & .69 & .71 \\
\hline $\begin{array}{l}\text { Which of the following best describes your } \\
\text { average grade in this school year? }^{d}\end{array}$ & .70 & .71 \\
\hline \multicolumn{3}{|l|}{ Time with friends } \\
\hline $\begin{array}{l}\text { During a typical week, on how many evenings } \\
\text { do you go out for fun and recreation? (Don't } \\
\text { count things you do with your parents or } \\
\text { other adult relatives.) }\end{array}$ & .62 & .61 \\
\hline $\begin{array}{l}\text { On average, how often (if ever) do you go out } \\
\text { with a date? }\end{array}$ & .47 & .47 \\
\hline $\begin{array}{l}\text { How often do your parents (or step-parents } \\
\text { or guardians) allow you to go out with } \\
\text { friends on a school night? }\end{array}$ & .58 & .57 \\
\hline \multicolumn{3}{|l|}{ 30-Day drug use } \\
\hline $\begin{array}{l}\text { How frequently have you smoked cigarettes } \\
\text { in the past } 30 \text { days? }\end{array}$ & .71 & .67 \\
\hline $\begin{array}{l}\text { On how many occasions have you had } \\
\text { alcoholic beverages to drink-more than } \\
\text { just a few sips... during the last } 30 \text { days? }{ }^{h}\end{array}$ & .72 & .68 \\
\hline $\begin{array}{l}\text { On how many occasions (if any) have you } \\
\text { used marijuana (grass, pot) or hashish (hash, } \\
\text { hash oil) during the last } 30 \text { days? } ?^{h}\end{array}$ & .62 & .65 \\
\hline \multicolumn{3}{|l|}{ Parental education $^{i}$} \\
\hline $\begin{array}{l}\text { What is the highest level of schooling your } \\
\text { mother completed?/What is the highest level } \\
\text { of schooling your father completed? (items } \\
\text { combined) }\end{array}$ & .95 & $\begin{array}{l}.95 \\
\text { (fixed) }\end{array}$ \\
\hline
\end{tabular}

${ }^{a} 1=$ Never to $4=$ often; ${ }^{b} 1=$ disagree to $5=$ agree; ${ }^{c} 1=$ never to $4=$ almost always; ${ }^{d} 1=\mathrm{D}$ ( 69 or below) to $9=\mathrm{A}(93-100)$; ${ }^{e} 1=$ less than one evening per week to $6=$ six or seven evenings per week; ${ }^{f} 1=$ never to $6=$ over three times a week; ${ }^{g} 1=$ none to $7=$ two packs or more per day; ${ }^{h} 1=0$ occasions to $7=40$ or more occasions; ${ }^{i} 1=$ completed grade school or less to $6=$ graduate school or professional school after college. 
Predictors

Four items measured parental involvement. Two of the items measured parental involvement with homework and were averaged into a single item, resulting in three variables used to create the parental involvement factor (Cronbach alpa $=.54)$. Risk taking was measured with two items (Cronbach alpa $=$ .76) that have been strong predictors of substance use (Schulenberg et al., 1996). Measures of academic success and commitment to school have been used in the past with this data set and were good predictors of substance use (Bryant et al., 2000). The school success construct was created using two items that assessed completion of school assignments and a third that assessed average school grades (Cronbach alpha $=.73$ ). Others have found that a measure of time spent with peers in the absence of an authority figure was a good predictor of adolescent deviance (Osgood et al., 1996). Thus, a three-item construct assessed the time that adolescents spent out with friends $($ Cronbach alpha $=.58)$ in the absence of parents or guardians.

\section{Ethnicity}

To assess ethnicity, students were asked "How do you describe yourself?" In the current paper, African American adolescents are those who chose the "Black or African American" category; European American adolescents are those who chose the "White or Caucasian" category; and Hispanic American adolescents are those who chose the "Mexican American or Chicano," the "Cuban American," the "Puerto Rican," or the "Other Latin American" category.

\section{Parental Education}

We were ultimately interested in examining ethnic differences in our model, making it important to include parental education as a control variable. Without controlling for potential educational disparity between groups, differences in the predictors of drug use might simply reflect educational differences rather than ethnic differences. Parental education was measured by taking the highest level of education reported for either the mother or the father.

\section{ANALYSES AND RESULTS}

All structural equation modeling (SEM) analyses were conducted using LISREL (Jöreskog \& Sörbom, 1996) with the maximum likelihood method of estimation. ${ }^{5}$ The SEM analyses were conducted using variance-covariance matrices that were created from the individually weighted scores of respondents; however, the SEM results are presented in standardized metric for ease of interpretation (Alwin, 1988). To determine the suitability of the models, several fit indices were used: the LISREL goodness-of-fit index (GFI), Chi-square of the estimated model $\left(\chi^{2}\right)$, root mean square error of approximation (RMSEA), non normed fit index (NNFI), and the comparative fit index (CFI). For the GFI, NNFI, and the CFI, values between .95 and 1.0 indicate that the model provides a good fit to the data, whereas the RMSEA should be below .06 (Hu \& Bentler, 1999). The GFI and the RMSEA are absolute fit indices and represent the extent to which the observed variances and covariances are accounted for by the model. The NNFI and the CFI are two different classes of incremental fit measures and indicate the extent to which the structural model improves upon the structural null or baseline model. As recommended by Bollen (1989), we chose several fit indices and at least one from each of the various "families of measurement."

\section{Preliminary Model Comparison Analyses}

Our general strategy was to develop and test models on one sample, and then confirm models on a separate sample. We tested a series of nested alternative models presented in Fig. 2 (against our hypothesized model as shown in Fig. 1) using the nationally representative data from the 1996 8thand 10th-grade cohorts. Parental education was included as a control variable for all nested models with direct effects on all other variables in the model;

\footnotetext{
${ }^{5} \mathrm{~A}$ potential problem with the maximum likelihood estimation is the assumption of multivariate normality. We were not as concerned about this issue as we might have been if we had a smaller sample, because maximum likelihood tends to be more robust with large sample sizes. As a cautionary measure, because the modal response for 30-day cigarette, alcohol, or drug use was "no use," the final model results were replicated using the generalized least squares estimation procedure because it does not assume multivariate normality (Hayduk, 1987). The pathways were virtually identical, and in all cases the fit indices were the same or provided a slightly better fit of the model using generalized least squares estimation.
} 


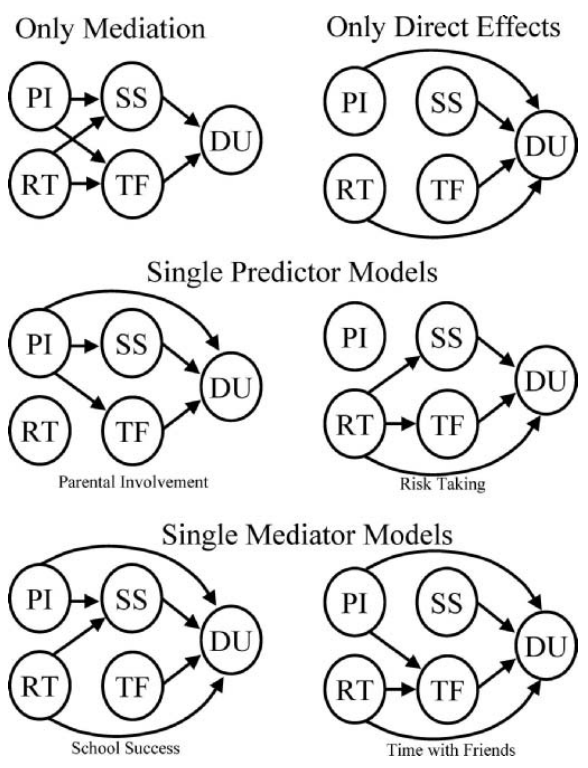

Fig. 2. Alternative models.

however, for ease of presentation this variable is not included in the diagrams of these models in Fig. 2. Because parental involvement and risk taking are intercorrelated, the disturbance terms (residual factor variance) of these factors were correlated in our model, but again for ease of presentation this is not included in the diagrams. Similarly, the disturbance terms for school success and time spent with friends were correlated but not displayed in Fig. 2. We examined whether "Only Mediation" or "Only Direct Effects" provided a better fit for the data, as well as whether both predictors were necessary in the model, by examining models with single predictors: "Parental Involvement as the Only Predictor" and "Risk Taking as the Only Predictor." Two additional models examined whether both mediators were necessary: "School Success as the Only Mediator" and "Out with Friends as the Only Mediator." The Chisquare difference tests in Table 2 show that all alternative models fit significantly worse than our original hypothesized model. In terms of absolute fit, all of the models fit well, with the mediation effects model fitting almost as well as the original hypothesized model; this provides additional support that the effects of parental involvement and risk taking on drug use are mediated by school success and time spent out with friends.

The hypothesized model was then tested for equivalence across the 1994, 1995, and 1996 cohorts through multi-group SEM analyses. It was found that there were no measurement- or structural-level differences in the model across the three cohorts for 8 th and 10th graders, further suggesting the veracity of the hypothesized model. Thus, based on these preliminary analyses, in the present study we used the nationally representative data of the 1994 and 1995 8th- and 10th-grade cohorts to describe our hypothesized model and test it for generalization across gender and ethnic differences. The 1994-1995 cohorts were combined (total $N \mathrm{~s}=12,715$ and 13,974 for 8th and 10th grade, respectively) so as to ensure adequate numbers of adolescents in each gender and ethnic group ( $N$ s for each grade, ethnic, and gender group can be found in Table 3). Preliminary

Table 2. Comparison of Alternative Models with 1996 Cohort

\begin{tabular}{|c|c|c|c|c|c|c|c|c|}
\hline \multirow[b]{2}{*}{ Model } & \multirow[b]{2}{*}{$\chi^{2}$} & \multirow[b]{2}{*}{$(d f)$} & \multirow[b]{2}{*}{ NNFI } & \multirow[b]{2}{*}{ CFI } & \multirow[b]{2}{*}{ GFI } & \multirow[b]{2}{*}{ RMSEA } & \multicolumn{2}{|c|}{$\begin{array}{c}\text { Compared with } \\
\text { hypothesized model }\end{array}$} \\
\hline & & & & & & & $\Delta \chi^{2}$ & $(\Delta d f)$ \\
\hline Only mediation (no direct effects) & 2097.88 & $(79)$ & .93 & .95 & .98 & .04 & $157.11^{*}$ & (3) \\
\hline Only direct effects (no mediation) & 3885.77 & $(80)$ & .87 & .90 & .96 & .06 & $1945.00^{*}$ & (4) \\
\hline \multicolumn{9}{|l|}{ Single predictor } \\
\hline Parent involvement & 3059.21 & $(79)$ & .90 & .92 & .97 & .05 & $1118.44^{*}$ & (3) \\
\hline Risk taking & 2687.72 & $(79)$ & .91 & .93 & .97 & .05 & $746.95^{*}$ & (3) \\
\hline \multicolumn{9}{|l|}{ Single mediator } \\
\hline School success & 3016.44 & $(78)$ & .90 & .92 & .97 & .05 & $1075.67^{*}$ & (2) \\
\hline Time with friends & 3038.55 & $(78)$ & .90 & .92 & .97 & .05 & $1097.78^{*}$ & (2) \\
\hline $\begin{array}{l}\text { Original hypothesized model (all } \\
\text { predictors and mediators) }\end{array}$ & 1940.77 & (76) & .93 & .95 & .98 & .04 & - & - \\
\hline
\end{tabular}

Note. For the NNFI, CFI, and the GFI, the larger the value the better the model fit. For the RMSEA and $\chi^{2}$, the lower the value the better the model fit. $N=13,244$ weighted cases.

${ }^{*} p<.001$. 


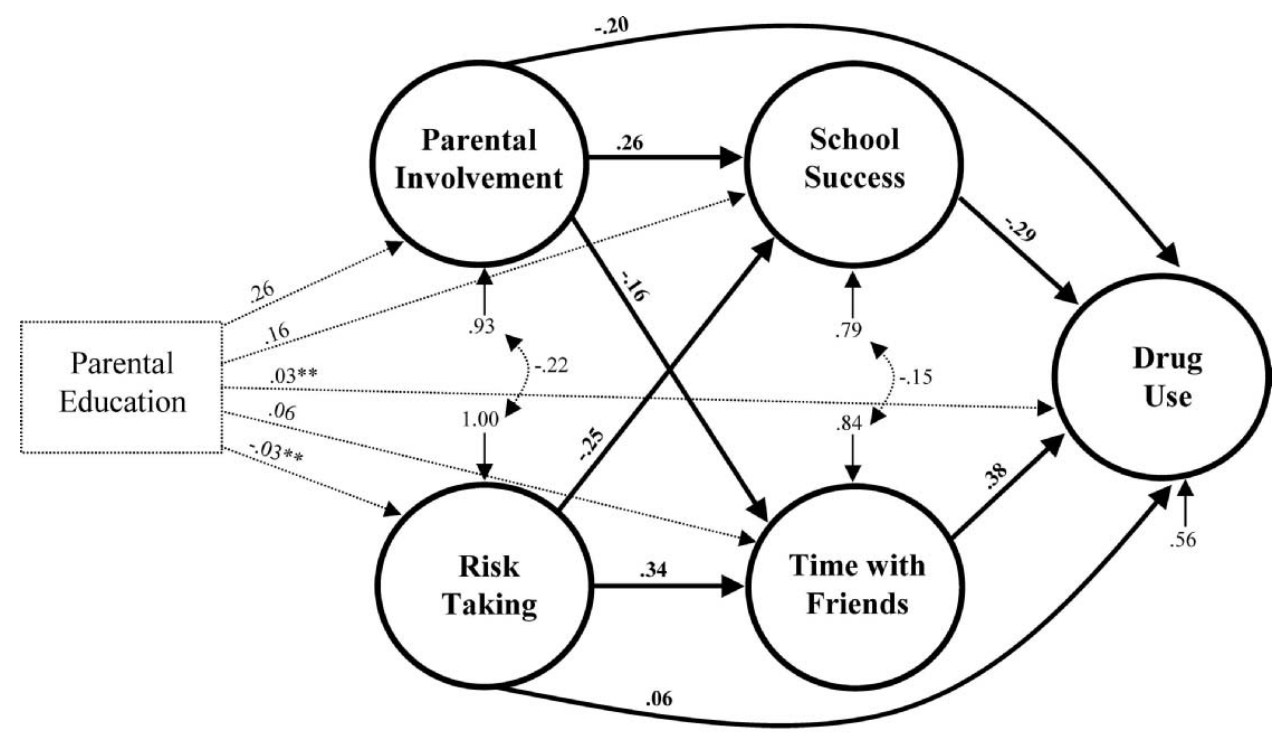

Note: Parental education entered as a control variable.

${ }^{*} \mathrm{p}<.05,{ }^{* *} \mathrm{p}<.01$. All pathways without an asterisk are significant to $\mathrm{p}<.001$ unless noted "ns."

Fig. 3. Structural equation model for 8 th grade $(N=12,715)$. Fit indices $\chi^{2}(76)=1819.42, \mathrm{NNFI}=.93$, $\mathrm{CFI}=.95, \mathrm{GFI}=.98, \mathrm{RMSEA}=.04$.

multi-group SEM analyses comparing 8th and 10th graders indicated significant and important differences between the grades (Pilgrim et al., 2000) and thus supported our decision to conduct separate analyses by grade. ${ }^{6}$

\section{Hypothesized Model}

\section{Total Sample}

Constructs were modeled in the typical factor analytic fashion, and thus the lambdas (the linkages

\footnotetext{
${ }^{6}$ We considered the possibility that single-parent households might moderate the relations between parental involvement and other constructs. Auxiliary analyses were conducted with the total sample (separately by grade) to compare single- versus twoparent households. There were very few differences between the two groups in the total and ethnic subgroup samples. One notable difference was that the path from parental involvement to time spent with friends was sometimes smaller in single-parent households than in two-parent households. We did not include this variable in the analyses reported here because findings were similar across two-parent and single-parent families, sample sizes became increasingly small when including the number of parents in the household, and the number of parents living at home is confounded by ethnicity. Furthermore, the number of parents in the household does not consider important extended family members who may be present outside the home, which may be of even greater importance for single-parent homes.
}

between the observed variable and the corresponding factor) can be interpreted as factor loadings. The standardized factor loadings for the measurement model are shown in Table 1, and all variables loaded significantly on their hypothesized latent constructs. The parental education construct was created using a single indicator with the error variance fixed to $10 \%$ of the observed variance (Hayduk, 1987). The hypothesized model fit the data well for both 8 th and 10 th graders as indicated by the fit indices, which can be found in Figs. 3 and 4.

Because parental involvement and risk taking are intercorrelated, the disturbance terms (residual factor variance) of these factors were correlated in our model. Similarly, the disturbance terms for time spent with friends and school success were correlated. This standard procedure of allowing disturbance terms to be correlated reflects the possibility that factors not explicitly included in the model affect the endogenous variables and correlations among them (Hargens, 1988).

As predicted, the effects of parental involvement and risk taking on adolescent drug use were mediated by school success and time spent out with friends (Figs. 3 and 4); the indirect, direct, and total effects for parental involvement and risk taking are reported separately in Table 3. We assessed mediation effects using LISREL, in which an 
Table 3. Indirect and Direct Effects on 30-Day Drug Use for Total Sample SEM and Six-Group SEM

\begin{tabular}{|c|c|c|c|c|c|c|c|c|}
\hline & \multicolumn{4}{|c|}{ 8th Grade } & \multicolumn{4}{|c|}{ 10th Grade } \\
\hline & $N$ & Indirect & Direct & Total & $N$ & Indirect & Direct & Total \\
\hline \multicolumn{9}{|l|}{ Parent involvement } \\
\hline $\begin{array}{l}\text { Total sample } \\
\text { Six-group model }\end{array}$ & 12,715 & -.13 & -.20 & -.33 & 13,974 & -.14 & -.12 & -.26 \\
\hline \multicolumn{9}{|l|}{ Girls } \\
\hline African American & 528 & $-.06^{* *}$ & -.29 & -.35 & 338 & -.12 & -.22 & -.34 \\
\hline European American & 2072 & -.16 & $-.08^{* *}$ & -.24 & 2573 & -.12 & -.13 & -.25 \\
\hline Hispanic American & 300 & -.13 & -.25 & -.38 & 278 & -.14 & -.10 & -.24 \\
\hline \multicolumn{9}{|l|}{ Boys } \\
\hline African American & 425 & -.13 & -.27 & -.40 & 271 & -.14 & -.12 & -.26 \\
\hline European American & 1796 & -.12 & -.24 & -.36 & 2492 & -.18 & -.11 & -.29 \\
\hline Hispanic American & 294 & -.15 & -.20 & -.35 & 235 & -.17 & -.13 & -.30 \\
\hline \multicolumn{9}{|l|}{ Risk taking } \\
\hline $\begin{array}{l}\text { Total sample } \\
\text { Six-group model }\end{array}$ & - & .19 & .06 & .25 & - & .19 & .14 & .32 \\
\hline \multicolumn{9}{|l|}{ Girls } \\
\hline African American & & $.03^{*}$ & .08 & .11 & & .15 & .17 & .32 \\
\hline European American & & .24 & .07 & .31 & & .18 & .21 & .39 \\
\hline Hispanic American & & .18 & .07 & .25 & & .16 & .09 & .25 \\
\hline \multicolumn{9}{|l|}{ Boys } \\
\hline African American & & .15 & .06 & .21 & & .16 & .09 & .25 \\
\hline European American & & .17 & .07 & .24 & & .17 & .09 & .26 \\
\hline Hispanic American & & .26 & .06 & .32 & & .16 & .09 & .25 \\
\hline
\end{tabular}

Note. Multiple group analyses were conducted with half samples. Pathways in the table are standardized, whereas those reported in the figures are common metric completely standardized. LISREL does not report the common metric for indirect effects. ${ }^{*} p<.05 .{ }^{* *} p<.01$. All reported pathways without an asterisk are significant to $p<.001$, unless noted by "ns."

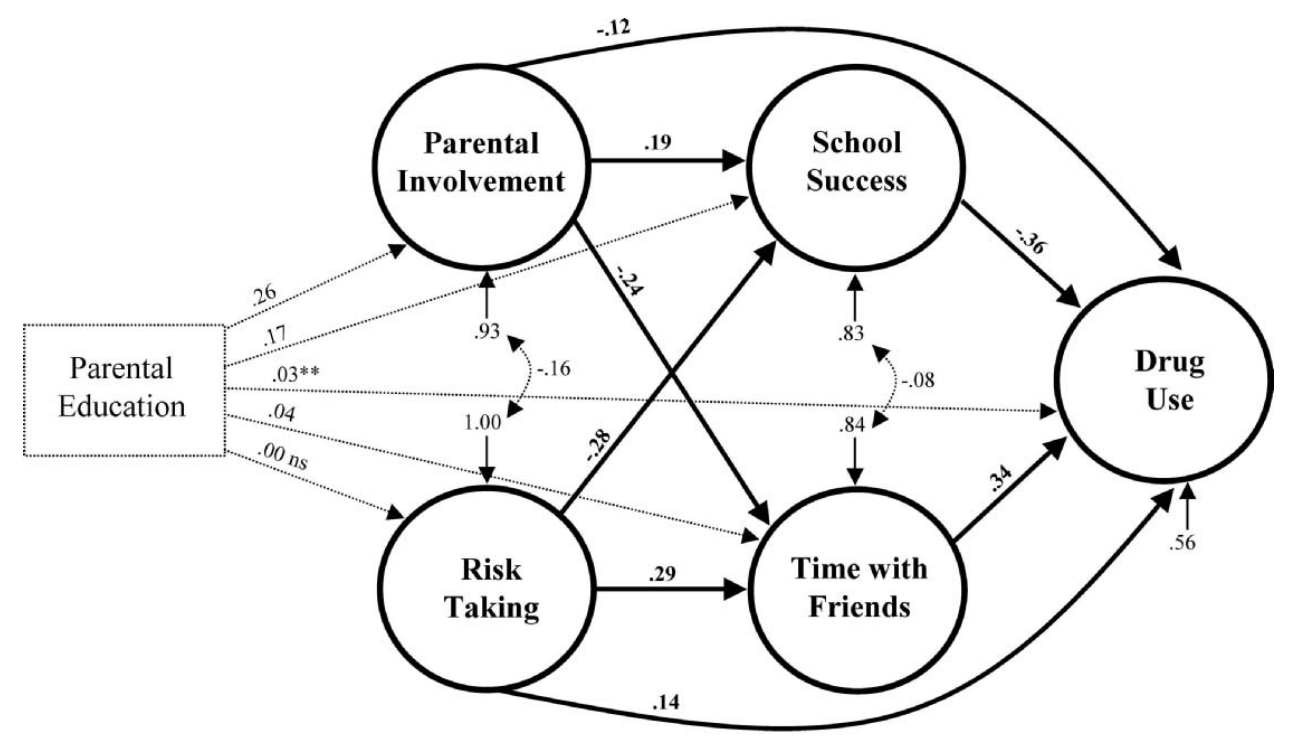

Note: Parental education entered as a control variable.

${ }^{*} \mathrm{p}<.05,{ }^{* *} \mathrm{p}<.01$. All pathways without an asterisk are significant to $\mathrm{p}<.001$ unless noted "ns."

Fig. 4. Structural equation model for 10th grade $(N=13,974)$. Fit indices $\chi^{2}(76)=2265.76, \mathrm{NNFI}=.92$,

$$
\mathrm{CFI}=.95, \mathrm{GFI}=.98, \mathrm{RMSEA}=.04 .
$$


indirect effect is a calculation of the total mediated effects of that predictor on an outcome (i.e., product of coefficients method). The indirect effects of parental involvement on drug use through school success and time spent with friends were similar in magnitude for 8th and 10th graders (betas $=-.13$ and -.14 , respectively). The indirect effects of risk taking on drug use through school success and time spent with friends were identical for 8th and 10th graders (betas $=.19$ ). Parental involvement also had a significant, direct effect on adolescent drug use (betas $=-.20$ and $-.12,8$ th and 10th grade, respectively). This significantly smaller direct effect for 10th graders in comparison to 8th graders $(t(26687)=$ $18.60, p<.001)$ resulted in a lower total effect of parental involvement on drug use, which suggests slightly less impact of parental involvement on drug use for older adolescents. On the other hand, risk taking had a greater direct effect on substance use for 10th graders than for 8th graders (betas $=.06$ and $.14 ; t(26687)=12.17, p<.001)$, resulting in a greater total effect of risk taking on substance use. This suggests that risk taking has a greater impact on drug use with older adolescents.

\section{Gender and Ethnicity}

The next phase of the study was to examine whether the model was generalizable across gender and ethnicity in multi-group analyses. The large sample enabled us to test simultaneously across gender and ethnicity (i.e., six-group SEMs) to consider potential gender-by-ethnicity interactions in relations among constructs. Thus, for this purpose, the large national sample is an important advantage. ${ }^{7}$

First, to ensure that the latent constructs were similar across all groups, a six-group test of the measurement model was conducted. Analyses indicated that for both 8th graders and 10th graders the measurement model provided a good fit with all observed variables loading significantly on the given latent constructs; loadings for only 2 of the 14 observed variables were significantly different across groups.

\footnotetext{
${ }^{7}$ One disadvantage of such a large sample, however, is that very small differences between groups may be statistically significant and are then overemphasized in the results. The most straightforward remedy was to conduct the analyses with the sample size cut in half, which still allowed us to conduct the six-group analyses, yet examine meaningful differences between groups. Thus, within the LISREL program syntax we designated the sample size as half of the true sample number.
}

The "limiting television" loading on the "parental involvement factor" was not invariant across groups: at 8th grade, it was lower for African American males (.30) and higher for European American females (.71) compared to the loading for the remainder of the total sample (.47); at 10th grade, it was lower for African American males (.45) than for the remainder of the total sample (.61). In addition, the "cigarette use" loading on the "30-day drug use" factor was not invariant across the gender by ethnic groups: at 8th grade, this loading was higher for European American females (.96) and males (.72) and lower for African American females (.29) compared to the remainder of the total sample (.51); at 10th grade, this loading was again higher for European American females (.81) and males (.67) and lower for Hispanic American males (.37) compared to the remainder of the total sample (.45). Given these small differences and the fact that these differences pertained to only 9 out of the total 84 comparisons of factor loadings, we deemed the measurement model an acceptably good fit and largely invariant across groups and proceeded to test for structural equivalence.

Overall, the fit indices reported in Figs. 5 and 6 indicate that the model fit the data well. As shown in Table 3, the total effects of both parental involvement and risk taking were significant across all age, gender, and ethnic groups, and in the large majority of cases, the beta coefficients were equivalent across the six groups at both grade levels. In terms of indirect effects, parental involvement was significantly mediated by school success and time with friends across all age, gender, and ethnic groups. As can be seen in Table 3, however, the indirect effect of parental involvement on drug use for 8th-grade African American girls (beta $=-.06$ ) was quite small compared with all other groups. A detailed examination of the SEM pathways indicates that this lower level of mediation can be explained partially by a lack of significant relationship between parental involvement and school success. This lower level of indirect effects for parental involvement did not occur among the 10th-grade African American girls; the indirect effect was similar to that for the other groups.

In terms of the indirect effect of risk taking on drug use, the pattern was the same as with parental involvement. Across all groups there was again a significant indirect effect of risk taking on drug use, but for African American 8th-grade girls this effect was small (beta $=.03$ ). Once again, however, by 10 th grade the indirect effect of risk taking on drug use was similar for African American girls 


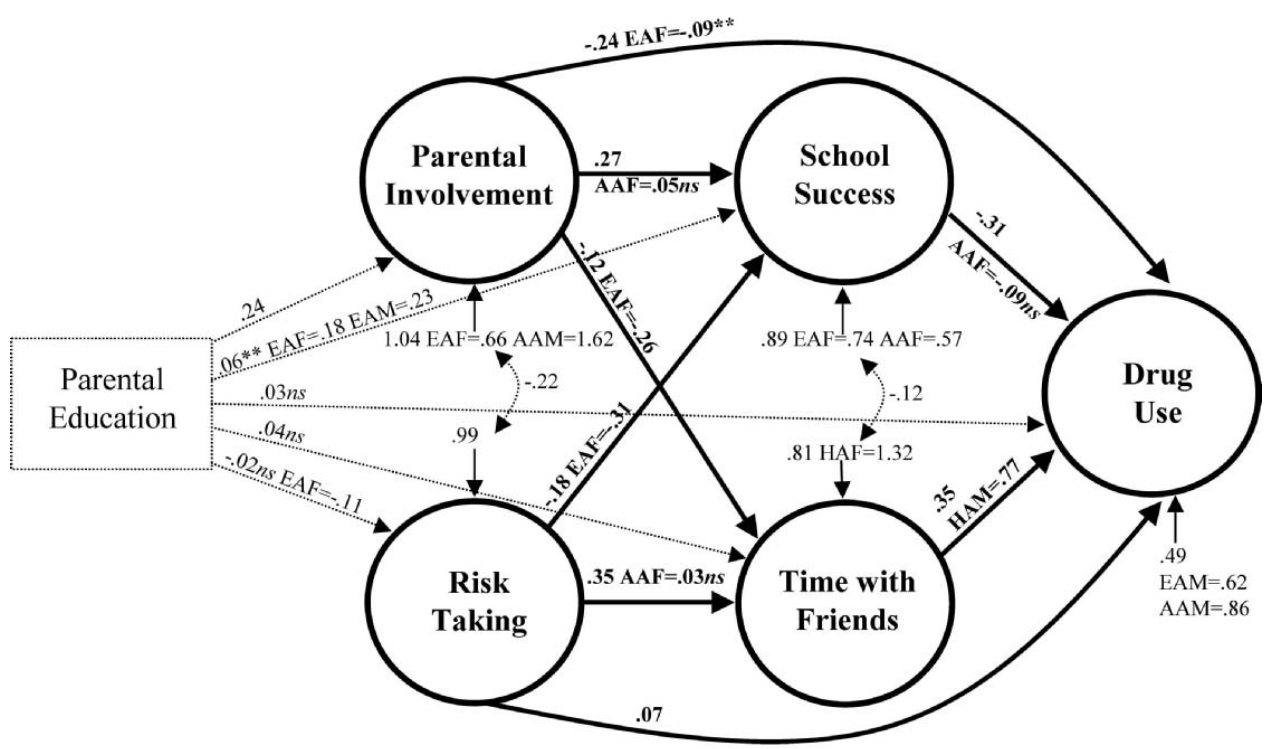

Note: Parental education entered as a control variable.

${ }^{*} \mathrm{p}<.05,{ }^{* *} \mathrm{p}<.01$. All pathways without an asterisk are significant to $\mathrm{p}<.001$ unless noted "ns."

Fig. 5. Six-group structural equation model for 8 th grade. Fit indices $\chi^{2}(579)=1438.05$, NNFI $=.94$, $\mathrm{CFI}=.94, \mathrm{GFI}=.95, \mathrm{RMSEA}=.04 . \mathrm{AA}$ : African American, EA: European American, HA: Hispanic American, F: Female, and M: Male. See Table 3 for sample sizes.

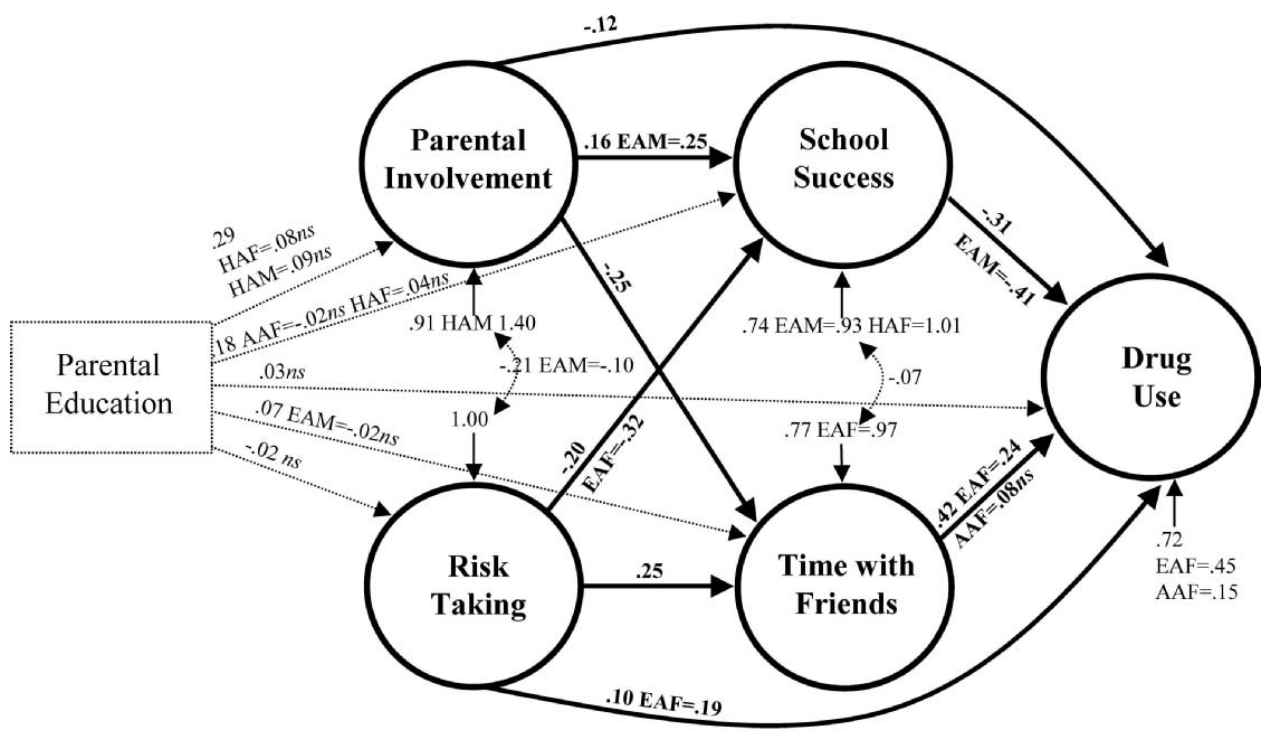

Note: Parental education entered as a control variable.

${ }^{*} \mathrm{p}<.05,{ }^{* *} \mathrm{p}<.01$. All pathways without an asterisk are significant to $\mathrm{p}<.001$ unless noted "ns."

Fig. 6. Six-group structural equation model for 10 th grade. Fit indices $\chi^{2}(579)=1462.22$, NNFI $=.94$, $\mathrm{CFI}=.95, \mathrm{GFI}=.95, \mathrm{RMSEA}=.04 . \mathrm{AA}$ : African American, EA: European American, HA: Hispanic American, F: Female, and M: Male. See Table 3 for sample sizes. 
compared with the other groups. From examination of the SEM pathways, it appears that for 8th-grade African American girls, risk taking is not associated with time spent with friends. Also, among 8th-grade European American girls and Hispanic American boys, the indirect effects of risk taking on drug use were slightly larger; however, this did not occur with the 10th-grade cohort. There were a few differences in the factor disturbance terms (see Figs. 5 and 6). ${ }^{8}$

\section{DISCUSSION}

The main question posed in this study was whether current social developmental theories of substance use, which include mediation processes, generalize across gender and ethnicity. To answer this question, we developed a mediation model of substance use based on current theory and research, and then tested this model with large, nationally representative samples across gender and ethnicity with both 8th and 10th graders. In terms of total effects, we found that parental involvement was significantly (negatively) predictive of adolescent substance use across all age, gender, and ethnic groups, supporting the generalizability of the effect of parental involvement on adolescent substance use. Similarly, risk taking was predictive of adolescent substance use across all age, gender, and ethnic groups. In terms of mediational processes, overall, the data indicate that across ethnicity and gender the effects of parental involvement and risk taking on adolescent drug use are mediated by school success and time spent with friends, supporting generalizability of mediational processes of parental involvement and risk taking. It is especially noteworthy that we found extensive measurement equivalence across the six gender-by-ethnicity groups at both 8 th and 10 th grade, indicating definitional invariance of the constructs of interest here; furthermore, while there was some significant variation in a few of the beta coefficients across some of

\footnotetext{
${ }^{8}$ Some of the completely standardized common metric disturbance terms were greater than 1.0, which is not necessarily problematic (see Alwin, 1988; Jöreskog, 1999). In particular, for a standardized multi-group common metric standardized solution, the latent variables are rescaled such that the sum of the weighted average of the variances (by the group sample size) are equal to 1 . The common metric disturbance term for each group is the product of the within-group standardized disturbance term and the common metric variance. Thus, even if all disturbance terms are less than 1 for each single group in the within standardized solution, there is no guarantee that the standardized common metric variances are less than 1.0.
}

the groups, the overall pattern reflects far more similarities across groups than differences. This highlights gender and ethnic similarity in social predictors and processes of substance use during adolescence.

For African American 8th-grade girls, though, the mediated effects were very small; however, by 10th grade the indirect effects were similar to the other groups. One possibility we considered was that parents of younger African American girls were on average more involved with their children, thus suppressing mediation. However, this does not appear likely given that parent involvement was still mediated by time spent with friends, and additional analyses indicated no significant differences for African American girls in the mean level of parental involvement. Despite these differences, the mediation model provided a good fit across groups, thus suggesting similarity in the developmental processes of substance use across gender and ethnicity. This similarity in mediation processes of drug use is good news for those interested in prevention programs targeted at groups of children with varying ethnicity. However, it does appear that there may be differences in the timing of importance of these mediating factors.

\section{Strengths, Limitations, and Future Directions}

An important strength of the current study is the nationally representative sample, which allowed us to develop and test our original model on one random national sample and replicate with another random national sample. With a large ethnically diverse sample, we were able to test for model invariance simultaneously across six subgroups defined by gender and ethnicity (African American, European American, and Hispanic American). This is an important advance, allowing us to expand scientific knowledge regarding similarities in the social developmental processes of substance use across ethnicity and gender.

There are, however, some noteworthy limitations. While the drug use measures (used as outcomes in this analysis) reflect a clear strength of the study, some of the other measures reflect potential limitations. Our operational definition for parental involvement differs somewhat from those used in other studies; others often include questions regarding parental warmth and specifics of parental monitoring. Our parental involvement construct assesses a basic and important level of involvement of the parent in the life of his/her child from the perspective of the adolescent. Our measures for other nondrug constructs are consistent in content with other 
measures in the literature and are reasonably reliable. In two cases (for parental involvement and time with friends), the Cronbach alpha coefficients were below .60 (.54 and .58 , respectively), and while this might be cause for some concern, the measurement models served to bring only the common variance into the structural models (thus pulling the measurement error out of the predictive models). The relatively large and similar factor loadings for the given items on these two factors provide further assurance that these two constructs are being reasonably measured in these analyses. Ultimately, we are limited to measures available in the data set, a common limitation of secondary data analyses of national studies (Brooks-Gunn et al., 1991).

It should be noted that because missing data was quite rare (except for sensation-seeking items) we used pairwise deletion in our analyses, which raises the possibility that our results might be biased because of the omission of items for some respondents in our sample. However, we did two things to address this concern. First, preliminary multi-group analyses were conducted comparing the use of listwise versus pairwise deletion for the covariance matrices and no differences were found. Second, most of the missing items were sensation-seeking, and as previously discussed, there were no differences in the covariances among the items for those respondents with sensation-seeking data and those without. Thus, we are reasonably confident that the sample in our study is representative of 8 th and 10th graders in the United States.

The current study relies solely on cross-sectional data, and thus causation cannot be established. While the temporal pathways make theoretical sense, they cannot be assumed as the only direction of effects. For example, while school difficulties clearly contribute to increased substance use over time (see Bryant et al., 2000), it is also possible that an adolescent's involvement with drugs may contribute to decreased school success. An important next step is to examine these mediation models across ethnicity with longitudinal data to consider temporal and causal sequences. Longitudinal data would allow for exploration of different onset and course of developmental processes across ethnicity. For example, in the current study we could only speculate about the changes in the mediation processes that might occur between 8th and 10th grade for boys and girls or African Americans girls.

The current study, like most studies comparing across ethnicity, allows for respondents to choose only one ethnicity, so the extent to which adolescents in our sample are of mixed ethnicity is not known. Harris (1999) has discussed the need to go beyond the single category of race in order to more accurately measure the ethnicity of respondents, and he highlights the need to acknowledge multi-racial adolescents in future studies (as the Monitoring the $\mathrm{Fu}$ ture study will do in future surveys). In addition, while we wish it were possible to examine different Hispanic subgroups within this study, subdividing the overall Hispanic group was not possible in this analysis due to sample size considerations (see Delva et al., 2005). Also, although we did not measure ethnic identity or acculturation (Brook et al., 1997), the comparisons we made in this study provide important descriptive information about ethnic similarities and differences in the social processes of adolescent substance use.

Although there was similarity of the model fit across ethnicity and gender, there are still some major differences with 8th-grade African American girls, suggesting that issues of ethnicity and gender should guide the development of additional substance use theories. For example, in the current study, while parental involvement was important for 8th-grade African American females, the indirect effects of parental involvement via school success and time with friends were not. There is a need for competing social developmental theories that would incorporate dimensions that might speak specifically to issues of greater importance for non-European American populations. Some have suggested that without incorporating cultural variables into the theories and research on such issues as substance use, prevention and treatment programs may not be effective across ethnic groups (Castro \& Hernandez, 2002). Although the current study restricted the number of variables for the sake of parsimony, Wallace et al. (2003) found that religion helped explain the lower prevalence rate of substance use among African American adolescents.

\section{Implications for Prevention}

Given the similarity in mediation processes across gender and ethnicity, it appears that drug abuse prevention efforts seeking to improve parentchild interactions should be successful across gender and with different ethnic groups. Substance abuse prevention programs that target parents and use a more family-centered approach have met with some success, and this research supports further 
efforts in this area (NIDA, 2003; Pilgrim et al., 1998; SAMHSA, 2002). However, often parents and educators have the sense that parents play a lesser role during adolescence and that prevention efforts should be focused on helping adolescents weather peer group pressure or on helping students "stay in school." Often the indirect role that parents play in substance use prevention is not understood. The current findings support the need for prevention programmers to help parents understand their role in substance use prevention. This study suggests that, across gender and ethnic groups, involved parents help the adolescent to be successful in school, which makes it more likely that the adolescent will not use drugs. Also, the more involved the parent is with the adolescent, the less time the child spends unsupervised with friends, and thus the potential for drug use declines. Prevention experts need to focus on providing schools and parents with the knowledge that parents do play a role in whether or not adolescents use drugs.

Also, it appears that specifically targeting youth risk takers for prevention efforts may be a good prevention strategy for adolescents among both gender and different ethnic groups. Those that are high risk takers can be identified early in adolescence for additional resources because they are less likely to do well in school and more likely to spend time with peers, thus increasing the chance of involvement with drugs.

Similarity across ethnicity is good news for prevention programmers who seek to reach a large audience with limited resources. However, even though domains targeted for prevention efforts (e.g., such as parent-child interactions) are similarly applied across ethnicity, there is still the need to incorporate non-European American cultural norms, values, and traditions into prevention efforts. In addition, even though the developmental process is the same, the possibility still remains that some risk and protective factors may be more or less applicable to certain ethnic groups. The weaker indirect links between parental involvement and drug use and between risk taking and drug use among African American 8thgrade girls in this study highlights this point.

In summary, our proposed model fits well across gender and ethnicity, suggesting much similarity across groups in the processes that lead to adolescent substance use. However, we did find some differences in the mediation processes and acknowledge that prevention efforts can be enhanced only by future development of theories that begin with, or at least incorporate, issues seen as potentially relevant to both genders and to non-European American groups.

\section{ACKNOWLEDGMENTS}

This research was supported by grants from the Robert Wood Johnson Foundation (\#032769) and the National Institute on Drug Abuse (\#DA01411). We thank Virginia Laetz for help with data analysis and Tanya Hart for editorial assistance.

\section{REFERENCES}

Alwin, D. F. (1988). Measurement and the interpretation of effects in structural equation models. In J. S. Long (Ed.), Common problems/proper solutions avoiding error in quantitative research (pp. 15-45). Thousand Oaks, CA: Sage.

Avenevoli, S., Sessa, F. M., \& Steinberg, L. (1999). Family structure, parenting practices, and adolescent adjustment: An ecological examination. In E. M. Hetherington (Ed.), Coping with divorce, single parenting, and remarriage: $A$ risk and resiliency perspective (pp. 65-90). Mahwah, NJ: Lawrence Erlbaum Associates.

Bachman, J. G., Johnston, L. D., \& O'Malley, P. M. (2001). The Monitoring the Future project after 27 years: Design and procedures. (Monitoring the Future Occasional Paper No. 54). Ann Arbor, MI: Institute for Social Research.

Bollen, K. A. (1989). Structural equations with latent variables. New York: John Wiley \& Sons.

Bray, J. H., Adams, G. J., Getz, J. G., \& Baer, P. E. (2001). Developmental, family, and ethnic influences on adolescent alcohol usage: A growth curve approach. Journal of Family Psychology, 15, 301-314.

Brook, J. S., Whiteman, M., Balka, E. B., Win, P. T., \& Gursen, M. D. (1997). African-American and Puerto Rican drug use: A longitudinal study. Journal of the American Academy of Child and Adolescent Psychiatry, 36, 1260-1268.

Brooks-Gunn, J., Phelps, E., \& Elder, G. H., Jr. (1991). Studying lives through time: Secondary data analyses in developmental psychology. Developmental Psychology, 27, 899-910.

Bryant, A. L., Schulenberg, J., Bachman, J. G., O’Malley, P. M., \& Johnston, L. D. (2000). Understanding the links among school misbehavior, academic achievement, and cigarette use: A national panel study of adolescents. Prevention Science, 1, 71-87.

Castro, F. G., \& Hernandez, E. (2002). Integrating cultural variables into drug abuse prevention and treatment with racial/ethnic minorities. Journal of Drug Issues, 32(3), 783810.

Costa, F. M., Jessor, R., \& Turbin, M. S. (1999). Transition into adolescent problem drinking: The role of psychosocial risk and protective factors. Journal of Studies on Alcohol, 60, 480490.

Crawford, A. M., Pentz, M. A., Chou, C., Li, C., \& Dwyer, J. H. (2003). Parallel developmental trajectories of sensation seeking and regular substance use in adolescents. Psychology of Addictive Behaviors, 17, 179-192.

Delva, J., Wallace, J. M., Jr., O’Malley, P. M., Bachman, J. G., Johnston, L. D., \& Schulenberg, J. E. (2005). The epidemiology of alcohol, marijuana, and cocaine use among Mexican 
American, Puerto Rican, Cuban American, and other Latin American eighth-grade students in the United States: 19912002. American Journal of Public Health, 95, 696-702.

Erickson, K. G., Crosnoe, R., \& Dornbusch, S. M. (2000). A social process model of adolescent deviance: Combining social control and differential perspectives. Journal of Youth and Adolescence, 29, 395-425.

Flannery, D. J., Vazsonyi, A. T., \& Rowe, D. C. (1996). Caucasian and Hispanic early drug use: Parenting, personality, and school adjustment. Journal of Early Adolescence, 16, 7189.

Gottfredson, D. C., \& Koper, C. S. (1997). Race and sex differences in the measurement of risk for drug use. Journal of Quantitative Criminology, 13, 325-347.

Griesler, P. C., \& Kandel, D. B. (1998). Ethnic differences in correlates of adolescent cigarette smoking. Journal of Adolescent Health, 23, 167-180.

Hargens, L. L. (1988). Estimating multi-equation models with correlated disturbance terms. In J. Scott Long (Ed.), Common problems/proper solutions: Avoiding error in quantitative research (pp. 65-83). Newbury Park, CA: Sage.

Harris, D. (1999). Patterns and Determinants of Adolescent Racial Identity. Seminar conducted at the Survey Research Center, Institute for Social Research, Ann Arbor, Michigan.

Hawkins, J. D., Catalano, R. F., \& Miller, J. Y. (1992). Risk and protective factors for alcohol and other drug problems in adolescence and early adulthood: Implications for substance use prevention. Psychological Bulletin, 112, 64-105.

Hawkins, J. D., \& Weis, J. G. (1985). The social developmental model: An integrated approach to delinquency prevention. Journal of Primary Prevention, 6, 73-97.

Hayduk, L. A. (1987). Structural equation modeling with LISREL essentials and advances. Baltimore, MD: Johns Hopkins University Press.

Herman, M. R., Dornbusch, S. M., Herron, M. C., \& Hertig, J. R. (1997). The influence of family regulation, connection, and psychological autonomy on six measures of adolescent functioning. Journal of Adolescent Research, 12, 34-67.

Hirschi, T. (1969). Causes of delinquency. Berkeley, CA: University of California Press.

Hu, L., \& Bentler, P. M. (1999). Cutoff criteria for fit indexes in covariance structure analysis: Conventional criteria versus new alternatives. Structural Equation Modeling, 6, 1-55.

Jacobson, K. C., \& Crockett, L. J. (2000). Parental monitoring and adolescent adjustment: An ecological perspective. Journal of Research on Adolescence, 10, 65-97.

Jessor, R. (1998). New perspectives on adolescent risk behavior. In R. Jessor (Ed.), New perspectives on adolescent risk behavior (pp. 1-10). Cambridge: Cambridge University Press.

Johnston, L. D., O'Malley, P. M., Bachman, J. G., \& Schulenberg, J. E. (2004). National survey results on drug use from the Monitoring the Future study, 1975-2003. Volume I: Secondary school students. Volume II: College students and adults ages 19-45. (NIH Publication Nos. 04-5507 \& 04-5508). Bethesda, MD: National Institute on Drug Abuse.

Jöreskog, K. G. (1999). How large can a standardized coefficient be? Retrieved February 2, 2005, from http://www.ss icentral.com/lisrel/column2.htm.

Jöreskog, K. G., \& Sörbom, D. (1996). LISREL 8: User's reference guide. Chicago: Scientific Software International.

Kish, L. (1965). Survey sampling. New York: Wiley.

Li, X., Feigelman, S., \& Stanton, B. (2000). Perceived parental monitoring and health risk behaviors among urban lowincome African-American children and adolescents. Journal of Adolescent Health, 27, 43-48.

Morgan-Lopez, A. A., Castro, F. G., Chassin, L., \& MacKinnon, D. P. (2003). A mediated model of cigarette use among Mexican American youth. Addictive Behaviors, 28, $583-589$.
Murguia, E., Chen, Z., \& Kaplan, H. B. (1998). A comparison of causal factors in drug use among Mexican Americans and non-Hispanic Whites. Social Science Quarterly, 79, 341-360.

National Institute on Drug Abuse (NIDA) (2003). Preventing drug use among children and adolescents: $A$ research-based guide for parents, educators, and community leaders (2nd ed., Booklet NCADI \#PHD1023A). Washington, DC: U.S. Department of Health \& Human Services.

Oetting, E. R., \& Donnermeyer, J. F. (1998). Primary socialization theory: The etiology of drug use and deviance. I. Substance Use and Misuse, 33, 995-1026.

Osgood, D. W., Wilson, J. K., O'Malley, P. M., Bachman, J. G., \& Johnston, L. D. (1996). Routine activities and individual deviant behavior. American Sociological Review, 61, 635-655.

Patterson, G. R., DeBaryshe, B. D., \& Ramsey, E. (1989). A developmental perspective on antisocial behavior. American Psychologist, 44, 329-335.

Pilgrim, C., \& Rueda-Riedle, A. (2003). The importance of social context in cross-cultural comparisons: First graders in Colombia and the United States. Journal of Genetic Psychology, 163(3), 283-295.

Pilgrim, C., Schulenberg, J., O'Malley, P. M., Bachman, J. G., \& Johnston, L. D. (2000). Mediators of parental influences on adolescent substance use: Grade, gender, and ethnic comparisons (1994-1996). (Monitoring the Future Occasional Paper No. 47). Ann Arbor, MI: Institute for Social Research.

Pilgrim, C., Abbey, A., Hendrickson, P., \& Lorenz, S. (1998). Implementation and impact of a family-based substance abuse prevention program in rural communities. The Journal of Primary Prevention, 18, 341-361.

Pilgrim, C., Luo, Q., Urberg, K. A., \& Fang, X. (1999). Influence of peers, parents, and individual characteristics on adolescent drug use in two cultures. Merrill-Palmer Quarterly, 45, 85107.

Reifman, A., Barnes, G. M., Dintcheff, B. A., Uhteg, L., \& Farrell, M. P. (2001). Health values buffer social-environmental risks for adolescent alcohol misuse. Addictive Behaviors, 15, 249251.

Roski, J., Perry, C. L., McGovern, P. G., Veblen-Mortenson, S., \& Farbakhsh, K. (1997). Psychosocial factors associated with alcohol use among young adolescent American Indians and Whites. Journal of Child and Adolescent Substance Abuse, 7, $1-18$.

Rowe, D. C., Vazsonyi, A. T., \& Flannery, D. J. (1994). No more than skin deep: Ethnic and racial similarity in developmental processes. Psychological Review, 101, 396-413.

Schulenberg, J., Maggs, J. L., Steinman, K., \& Zucker, R. A. (2001). Development matters: Taking the long view on substance abuse etiology and intervention during adolescence. In P. M. Monti, S. M. Colby, \& T. A. O'Leary (Eds.), Adolescents, alcohol, and substance abuse: Reaching teens through brief intervention (pp. 19-57). New York: Guilford Press.

Schulenberg, J., Wadsworth, K. N., O’Malley, P. M., Bachman, J. G., \& Johnston, L. D. (1996). Adolescent risk factors for binge drinking during the transition to young adulthood: Variable- and pattern-centered approaches to change. Developmental Psychology, 32, 659-674.

Strait, S. C. (1999). Drug use among Hispanic youth: Examining common and unique contributing factors. Hispanic Journal of Behavioral Sciences, 21, 89-103.

Substance Abuse and Mental Health Services Administration (SAMHSA). (2002). 2002 Science-Based Prevention Programs and Principles. Washington, DC: U.S. Department of Health and Human Services. Retrieved May 11, 2005 from http://www.modelprograms.samhsa.gov.

Swaim, R. C., Bates, S. C., \& Chavez, E. L. (1998). Structural equation socialization model of substance use among MexicanAmerican and White non-Hispanic school dropouts. Journal of Adolescent Health, 23, 128-138. 
Thornberry, T. P. (1987). Toward an interaction theory of delinquency. Criminology, 25, 851-891.

Vega, W. A., Zimmerman, R. S., Warheit, G. J., Apospori, E., \& Gil, A. G. (1998). Risk factors for early adolescent drug use in four ethnic and racial groups. In P. B. Organista, K. M. Chun, \& G. Marín (Eds.), Readings in ethnic psychology (pp. 178-187). New York: Routledge.

Wallace, J. M., Jr., Brown, T. N., Bachman, J. G., \& LaVeist, T. A. (2003). The influence of race and religion on abstinence from alcohol, cigarettes and marijuana among adolescents. Journal of Studies on Alcohol, 64(6), 843-848.
Wang, G. T., Bahr, S. J., \& Marcos, A. C. (1995). Family bonds and adolescent substance use: An ethnic group comparison. In C. K. Jacobson (Ed.), American families: Issues in race and ethnicity (pp. 463-492). New York: Garland Publishing.

Wills, T. A., Resko, J. A., Ainette, M. G., \& Mendoza, D. (2004). Role of parent support and peer support in adolescent substance use: A test of mediated effects. Psychology of Addictive Behaviors, 18, 122-134.

Zuckerman, M. (1994). Behavioral expressions and biosocial bases of sensation seeking. New York: Cambridge University Press. 